\title{
Primary Restorative Transmission Line Selection for Myanmar's Electric Power System
}

\author{
Yong-Hak Kim*, In-Jun Song ${ }^{\dagger}$, Byung-Tae Jang* and Yong-Ho An*
}

\begin{abstract}
Power system restoration following a massive or complete blackout starts with energizing the primary restorative transmission system. During this primary restoration process, unexpected overvoltage may happen due to nonlinear interaction between the unloaded transformer and the transmission system. In the case of the Myanmar electric power system, there are so many wide outage experiences, including complete blackout cases, caused by $230 \mathrm{kV}$ line faults and so on. Consequently, Myanmar's system operators have been well trained to deal with wide blackouts. Howver, system blackout restoration has been conducted by relying on the experience of only a few specialists. So, more scientific analysis is required to meet the requirements necessary to ensure fast and reliable system restoration. This paper presents analytical results on the primary restorative transmission system of Myanmar, focusing on the problems during the early restoration process. Methodologies are presented that handle load pick-up, terminal voltage and the reactive capability limitation of black-start generators to compensate the Ferranti effect. Static and dynamic simulation with the PSSolution and EMTDC programs respectively for the six cases are performed in order to select the primary restorative transmission lines.
\end{abstract}

Keywords: Black start, Primary restorative transmission system, EMTDC, Myanmar electric power system

\section{Introduction}

A power system cannot possibly be free from various problems such as line faults, lightning strikes, equipment failure and so on. However, it is certain that fast system restoration following a blackout is very important as a long lasting widespread electrical outage seriously affects the national economy as well as the security of society in general. As the restoration method is dependent on the fault, voltage level, the structure of transmission network, and a nation's generators, the strategy required is different from country to country. However, it is clear that during the first stage of restoration, black-start generators supply some large capacity generators through primary restorative transmission lines in cases of wide area blackouts [1]-[3].

A major process of power system restoration following a complete or wide area blackout would be the energizing of primary restorative transmission lines. This process begins by starting black-start generators, such as hydro generators or gas turbines, and then charging primary restorative transmission lines to supply cranking power for large generation plants [4]-[6]. After the massive blackout, power system restoration is achieved by the operator's expert knowledge and experience. Huge disturbances as well as damage to equipment during the restoration process can be caused if the blackout situation is not properly diagnosed

$\dagger \quad$ Corresponding Author: Korea Electric Power Research Institute, Korea. (injun@kepco.co.kr)

* Korea Electric Power Research Institute, Korea. (kimyh@kepri.re.kr)

Received: August 27, 2009; Accepted: March 3, 2010 by the operator or if mistakes are made in the restoration process. Therefore, quick and reliable diagnosis and restoration are required. Power systems of radial structure have a higher possibility of experiencing a massive blackout than a mashed structure.

The static analysis of the primary restorative transmission systems are focussed on three problems. One is the overvoltage of the primary restorative transmission systems, another is the primary restorative transmission line charging, and the other is the reactive capability of a black-start generators. The dynamic analysis of the primary restorative transmission systems is focussed on the possible existence of the harmonic resonance. Harmonic resonance phenomenon is known as the unexpected over-voltage that may happen due to nonlinear interaction between the unloaded transformer and the transmission system [7]-[9].

In the case of Myanmar's electric power system, numerous wide outage experiences occur, including complete blackout cases by $230 \mathrm{kV}$ line fault, and so on. Consequently, MEPE's (Myanmar Electric Power Enterprise) system operators have been trained well to handle wide blackouts. But system blackout restoration has been conducted by relying on only a few specialists and their years of experience. However, it will be difficult to depend on only a few experienced specialists for an expanded power system in the future. Therefore, scientific analysis is required to meet the requirements of fast and reliable system restoration.

In this paper, we analyze of Myanmar's electric power system in order to select the primary restorative transmission lines. Methodologies are presented that handle load pick-up, terminal voltage and the reactive capability limitation of black-start generators to compensate for the Ferranti 
effect. Static and dynamic simulation with the PSSolution and EMTDC programs respectively are performed in order to select the primary restorative transmission lines. The simulations for six cases are carried out to select these primary restorative transmission lines.

\section{The Present State of Electric Power Systems in Myanmar}

The Transmission network employs $230 \mathrm{kV}, 132 \mathrm{kV}$ and $66 \mathrm{kV}$ for its transmission system, as well as $33 \mathrm{kV}, 11 \mathrm{kV}$ and $6.6 \mathrm{kV}$ for its distribution system. The present power systems can be divided into two parts. The $230 \mathrm{kV}$ system runs from the Thazi substation south towards the Yangon area, while the $132 \mathrm{kV}$ system covers the central regions around the Thazi substation and all northern regions. These two different voltage systems operate geographically independent of each other. There is a possibility of system blackout or facility overloading when some facilities are in outage. In many cases, when a high voltage transmission line trips, the Myanmar grid divides into two islands (Yangon and outside Yangon). This results in significant power imbalance in each island. The power imbalance induces a severe frequency and voltage fluctuation that causes power supply interruption.

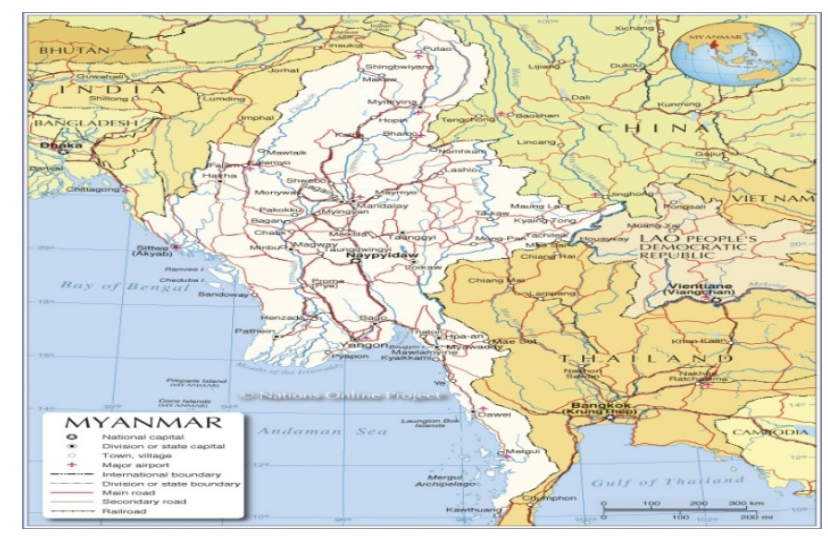

Fig. 1. The location of Myanmar.

A long transmission line needs a reactive power compensation facility to compensate for voltage drops at the receiving end in the normal state. However, in MEPE systems, reactive power compensation facilities are not installed enough to control system voltage and most power transformers' tap changers are operated in fixed tap position. So, system voltage is controlled by the generators' terminal voltage and load supply. Therefore, step-up transformers' tap ratio and tap position is a decisive factor of system voltage. Most step-up transformers have a high tap ratio to keep low voltage from the receiving end BUS, which causes high system voltage during the initial charging of a long primary restoration line, causing difficulties in voltage control during system restoration. The Table below shows the tap operation status of step-up transformers installed in power stations.
Table 1. Step-up Transformers' Tap Operation Status

\begin{tabular}{c|c|c|c|c|c}
\hline $\begin{array}{c}\text { Station } \\
\text { Name }\end{array}$ & $\begin{array}{c}\text { Voltage } \\
\text { Level(kV) }\end{array}$ & $\begin{array}{c}\text { Capacity } \\
\text { (MVA) }\end{array}$ & $\begin{array}{c}\text { Tap Voltage } \\
\text { (Upper Limit } \\
\text { Lower Limit) }\end{array}$ & $\begin{array}{c}\text { No. } \\
\text { of Tap }\end{array}$ & $\begin{array}{c}\text { Present } \\
\text { Tap } \\
\text { Position }\end{array}$ \\
\hline Shwedaung & $230 / 66 / 11$ & 100 & $\begin{array}{c}260.7 \sim 199.3, \\
( \pm 1.67 \times 8 \%)\end{array}$ & 17 & 13 \\
\hline Paunglaung & $245 / 11$ & 85 & $\begin{array}{c}257.25 \sim 232.75, \\
( \pm 2.5 \%)\end{array}$ & 5 & 3 \\
\hline Hlawga & $230 / 33 / 11$ & 60 & $230 \sim 200$ & 4 & 3 \\
\hline \multirow{2}{*}{ Lawpita } & $132 / 11$ & 90 & No Tap & & \\
\cline { 2 - 6 } & $230 / 132$ & 100 & $230 \sim 210$ & 3 & 3 \\
\hline
\end{tabular}

\section{Study Methodology and Approach}

The first thing for primary restoration line selection is to choose a black-start generator. Conditions for black-start generator selection are as follows:

- The generator can run with self power as soon as possible. - The generator has to secure enough energy sources to supply power regardless of weather conditions or external causes.

- The generator can supply reactive power to $80 \%$ of the capacity.

Usually, hydro power or pumping-up power generators satisfied with the conditions mentioned above are used for black-start generators. After selecting a black-start generator, a big capacity generator is selected to supply as much power as possible to the outage areas. Then, transmission lines between the black-start generators and the big capacity generator are listed to select a primary restoration line with the priority being the shortest distance.

When a transmission line is energized on no-load condition, overvoltage can be induced at the receiving end due to the Ferranti effect. This overvoltage has an effect on the dielectric strength of buses, transformers, and generators which are connected at the receiving end of the transmission line. System simulations are required to review the Ferranti effect and to select the appropriate primary restoration line from the transmission line lists between the black-start generators and the big capacity generator. The items below are studied from the system simulations.

- Required load amount at substations to compensate the Ferranti effect or to balance with the charging capacity.

- Terminal voltage of black-start generators to reduce overvoltage at the receiving end.

- Reactive power capability limitation of black-start generators to supply reactive power for the charging capacity of a primary restoration line, which studies the selfexcitation of the generator.

The PSSolution program is used for static simulation and EMTDC for the dynamic simulation. As the system simulation results, the best line qualified for the primary restoration line is selected. Requirements for the primary restoration line are as follows: 
- Terminal voltage of black-start generators is within the available range from 0.9P.U to 1.0P.U.

- Reactive power to cover the charging capacity of the primary restoration line on load or no-load can be supplied.

- Substation voltage is under $1.1 \mathrm{P} . \mathrm{U}$ in the $132 \mathrm{kV}$ system and $1.05 \mathrm{P} . \mathrm{U}$ in the $230 \mathrm{kV}$ system.

- There is no problem against transient phenomenon by switching and ferro-resonance of the transformer.

Fig. 2 below shows the general process for primary restorative line selection.

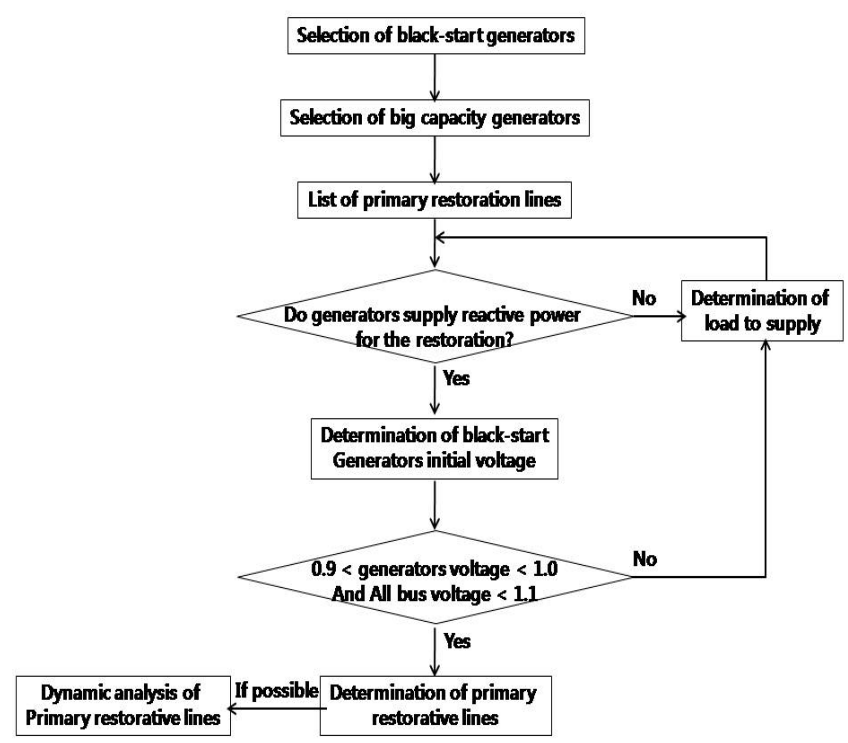

Fig. 2. Flow chart for primary restorative line selection.

\section{Primary restorative system simulation}

Since the generators in Myanmar are, for the most part, hydro generators or gas turbines which can start by themselves, it is not possible to select primary restorative transmission lines in general to supply cranking power for large generation plants. Therefore, this paper reports selecting primary restorative transmission lines which make reactive power cooperation between generators to control the system voltage rising due to charging the no-load long distance transmission lines. Lawpita $\mathrm{H} / \mathrm{P}$ and Paunglaung $\mathrm{H} / \mathrm{P}$ are selected as the black-start generators because they produce the most electric power and have the largest generation capacity. Paunglaung H/P, Kinda H/P, Hlawga G/P, and Shwedaung $\mathrm{G} / \mathrm{P}$ are selected as the priority participation generators because of their relatively large generation capacity for reactive power cooperation.

Accordingly, the lines from the black-start generators to priority participation generators are selected as primary restorative transmission lines, that is, Lawpita H/P - Paunglaung H/P, Lawpita H/P - Hlawga G/P, Lawpita H/P Kinda H/P, Paunglaung H/P - Shwedaung G/P, Paunglaung $\mathrm{H} / \mathrm{P}$ - Hlawga G/P. The cases for the primary restorative transmission lines are listed below.
- Case 1: Lawpita H/P $\rightarrow$ Taungoo S/S $\rightarrow$ Thephyu S/S $\rightarrow$ Pyinmana $\mathrm{S} / \mathrm{S} \rightarrow$ Paunglaung $\mathrm{H} / \mathrm{P}$

- Case 2: Lawpita $\mathrm{H} / \mathrm{P} \rightarrow$ Tigit $\mathrm{S} / \mathrm{S} \rightarrow$ Kalaw $\mathrm{S} / \mathrm{S} \rightarrow$ Thazi $\mathrm{S} / \mathrm{S} \rightarrow$ Pyinmana $\mathrm{S} / \mathrm{S} \rightarrow$ Paunglaung $\mathrm{H} / \mathrm{P}$

- Case 3: Lawpita $\mathrm{H} / \mathrm{P} \rightarrow$ Taungoo $\mathrm{S} / \mathrm{S} \rightarrow$ Tharyargone $\mathrm{S} / \mathrm{S} \rightarrow$ Kamarnat $\mathrm{S} / \mathrm{S} \rightarrow$ Hlawga G/P

- Case 4: Lawpita $\mathrm{H} / \mathrm{P} \rightarrow$ Tigit $\mathrm{S} / \mathrm{S} \rightarrow$ Kalaw $\mathrm{S} / \mathrm{S} \rightarrow$ Thazi $\mathrm{S} / \mathrm{S} \rightarrow$ Kinda $\mathrm{H} / \mathrm{P}$

- Case 5: Paunglaung H/P $\rightarrow$ Pyinmana $\mathrm{S} / \mathrm{S} \rightarrow$ Naypyitaw $\mathrm{S} / \mathrm{S} \rightarrow$ Taungdwigyi $\mathrm{S} / \mathrm{S} \rightarrow$ Shwedaung G/P

- Case 6: Paunglaung H/P $\rightarrow$ Pyinmana $\mathrm{S} / \mathrm{S} \rightarrow$ Thephyu $\mathrm{S} / \mathrm{S} \rightarrow$ Taungoo S/S $\rightarrow$ Tharyargone $\mathrm{S} / \mathrm{S} \rightarrow$ Kamarnat $\mathrm{S} / \mathrm{S} \rightarrow$ Hlawga G/P

Static and dynamic simulations for six cases are carried out in order to select primary restorative transmission lines. Fig. 3 is a simple diagram of the power system network showing the restorative transmission lines.

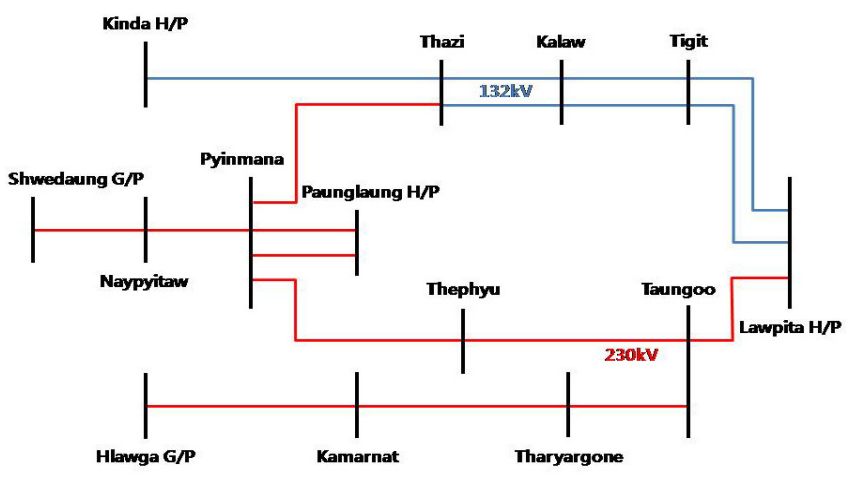

Fig. 3. Simple diagram of power system network.

\subsection{Static Simulation}

The PSSolution program is used for static simulation, and the results of the static simulation are presented in Tables 2 and 3 .

Table 2 is the result of the static simulation for Case 1 4, that is, Lawpita $\mathrm{H} / \mathrm{P}$ is used with the black-start generators. Cases 1 and 2 are the main and reserve primary restorative transmission lines, respectively, between Lawpita $\mathrm{H} / \mathrm{P}$ and Paunglaung H/P. In Table 2, Cases 1, 3 and 4 are satisfied with both the reactive power limits of the black-start generators and overvoltage conditions of the end BUS. But, Case 2 is not satisfied with the overvoltage condition of the receiving end BUS, even after charging with 0.91 [pu]. After charging the lines with a 17.74 MW and 7.86 MVar load supply at Thazi S/S $132 \mathrm{kV}$ BUS, Case 2-1 is satisfied with both conditions.

Table 3 is the result of the static simulation for Case 5 6, that is, where Paunglaung $\mathrm{H} / \mathrm{P}$ is used with the black-start generators. When charging the lines with 0.95 [pu], Table 3 shows that the Paunglaung generator \#1, 2, 3 and 4 unit can supply reactive power without any problem through the primary restorative line. However, the receiving end substation voltage is a little high. Therefore, $20 \mathrm{MVAr}$ reactive power at Shwedaung S/S in Case 5 and the load supply at Taun- 
goo $\mathrm{S} / \mathrm{S}$ in Case 6 respectively are required to reduce receiving end voltage when charging primary restorative transmission lines.

In Table 3, receiving end voltage can be reduced under the voltage limit by charging the lines with lower terminal voltage than $0.95[\mathrm{pu}]$. But the generator terminal voltage of Paunglaung H/P cannot be lowered below 0.94 [pu] because of the generator's mechanical characteristic. When the no-load long transmission line is charged, the receiving end voltage increases higher than the sending end voltage due to the Ferranti effect. The high tap ratio setting end causes more severe voltage increases at the receiving end. This voltage increasing at the receiving end can cause difficulties in system blackout restoration. Therefore, it is necessary to operate the step-up transformer tap ratio as low as possible considering the step-up transformer tap voltage ranges and receiving end voltage in both normal and abnormal states.

Table 2. The result of the static simulation for Case 1 4

\begin{tabular}{|c|c|c|c|c|c|c|c|}
\hline & \multicolumn{4}{|c|}{ Lawpita Gen. $\# 1,2,3,4,5,6$} & \multirow{2}{*}{\begin{tabular}{|c|}
$\begin{array}{c}230 \mathrm{kV} \\
\text { Paunlaung } \\
\text { BUS }\end{array}$ \\
$\mathrm{V}[\mathrm{pu}]$ \\
\end{tabular}} & \multirow{2}{*}{$\begin{array}{c}230 \mathrm{kV} \\
\text { Hlawga } \\
\text { BUS }\end{array}$} & \multirow[t]{2}{*}{$\begin{array}{c}132 \mathrm{kV} \\
\text { Kinda } \\
\text { BUS }\end{array}$} \\
\hline & Qmax & Qmin & Q & $\mathrm{V}[\mathrm{pu}]$ & & & \\
\hline Case 1 & 18.6 & $\mid-12.4$ & -6.96 & 0.95 & 1.031 & & \\
\hline Case 2 & 18.6 & -12.4 & -7.12 & 0.91 & 1.076 & & \\
\hline Case 2-1 & 18.6 & -12.4 & -5.64 & 0.93 & 1.044 & & \\
\hline Case 3 & 18.6 & $\mid-12.4$ & -7.45 & 0.94 & & 1.043 & \\
\hline Case 4 & 18.6 & -12.4 & -4.24 & 0.94 & & & 0.998 \\
\hline
\end{tabular}

Table 3. The result of the static simulation for Case 5 6

\begin{tabular}{c|c|c|c|c|c|c}
\hline & \multicolumn{4}{|c|}{ Paunlaung. Gen \#1,2,3,4 } & $\begin{array}{c}230 \mathrm{kV} \\
\text { Shwedaung BUS }\end{array}$ & $\begin{array}{c}230 \mathrm{kV} \\
\text { Hlawga BUS }\end{array}$ \\
\cline { 2 - 7 } & Qmax & Qmin & Q & V[pu $]$ & V[pu $]$ & \\
\hline Case 5 & 46.8 & -31.2 & -13.27 & 0.95 & 1.071 & \\
\hline Case 6 & 18.6 & -12.4 & -12.19 & 0.95 & & 1.081 \\
\hline
\end{tabular}

\subsection{Dynamic Simulation}

EMTDC is used for dynamic simulation. Three Phase RMS voltage at the black-start plant and Phase RMS voltage at the priority participation plant are investigated with the results of the dynamic simulations. The results of the dynamic simulations are shown below.

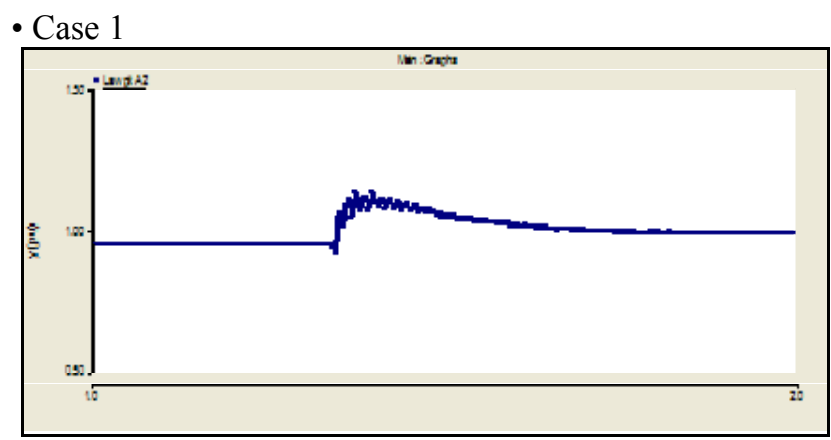

Fig. 4. 230kV Three phase RMS voltage at Lawpita H/P.

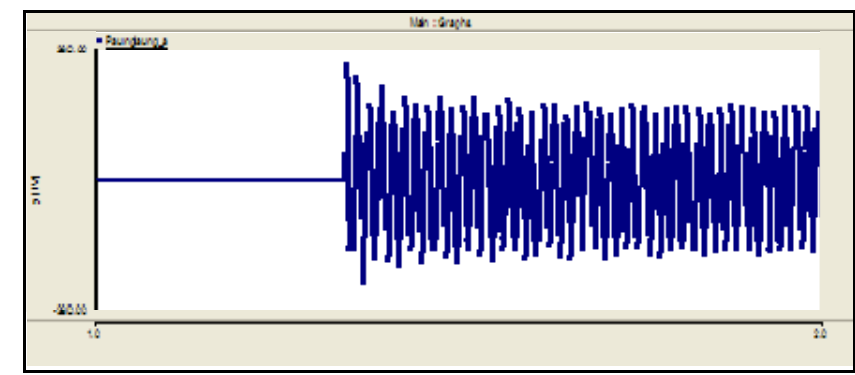

Fig. 5. 230kV Single phase RMS voltage at Paunglaung H/P.

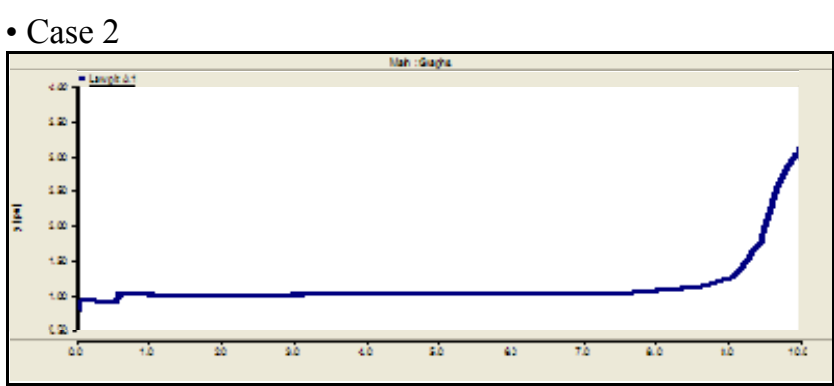

Fig. 6. $132 \mathrm{kV}$ Three phase RMS voltage at Lawpita H/P.

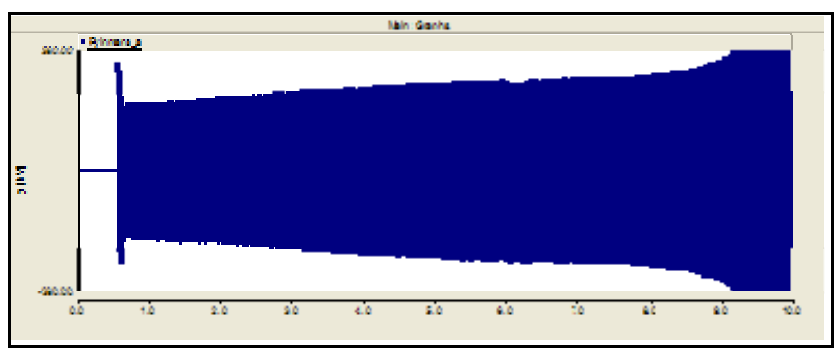

Fig. 7. 230kV Single phase voltage at Pyinmana S/S.

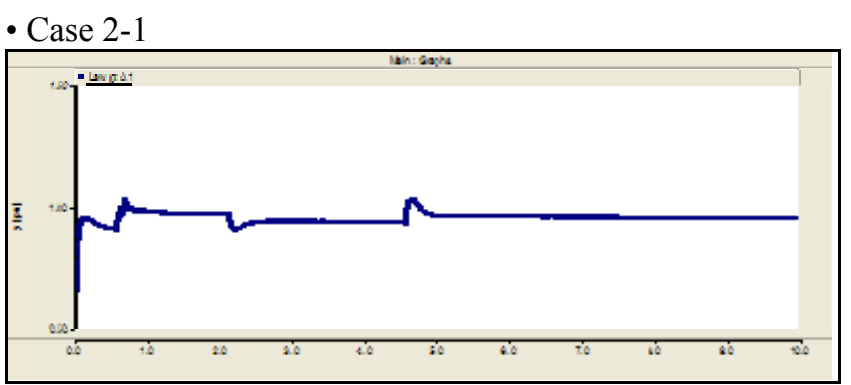

Fig. 8. $132 \mathrm{kV}$ Three phase RMS voltage at Lawpita H/P after load supply.

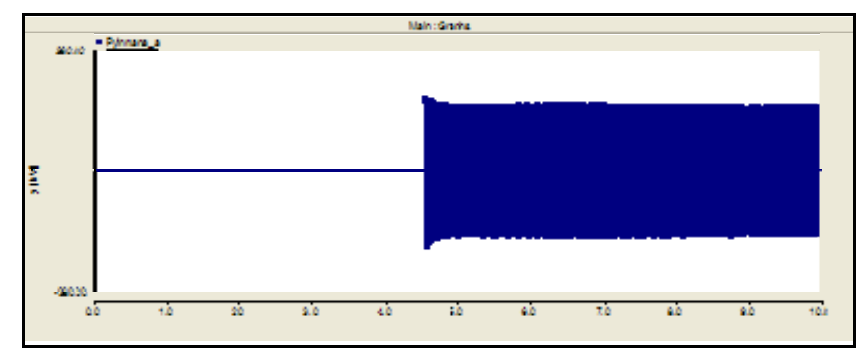

Fig. 9. $230 \mathrm{kV}$ Single phase voltage at Pyinmana $\mathrm{S} / \mathrm{S}$ after load supply. 


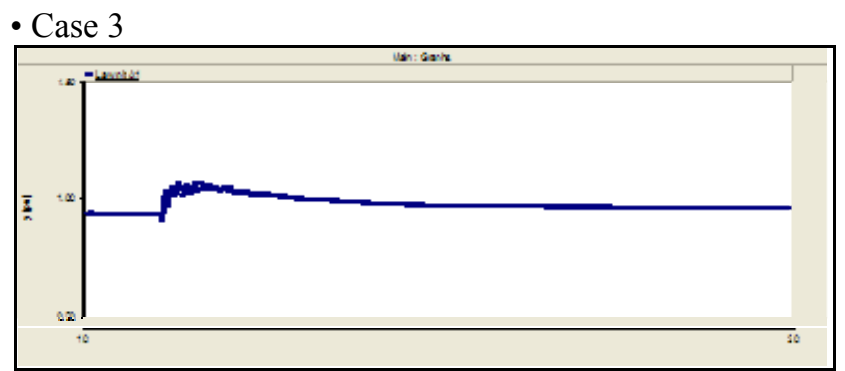

Fig. 10. 230kV Three phase RMS voltage at Lawpita H/P.

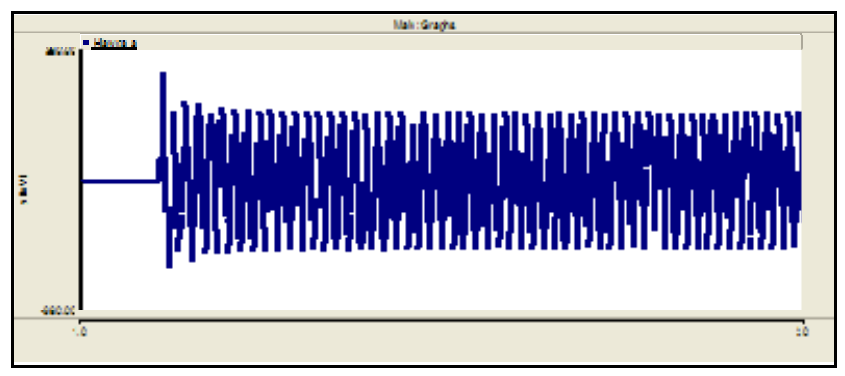

Fig. 11. 230kV Sing phase voltage at Hlawga G/P.

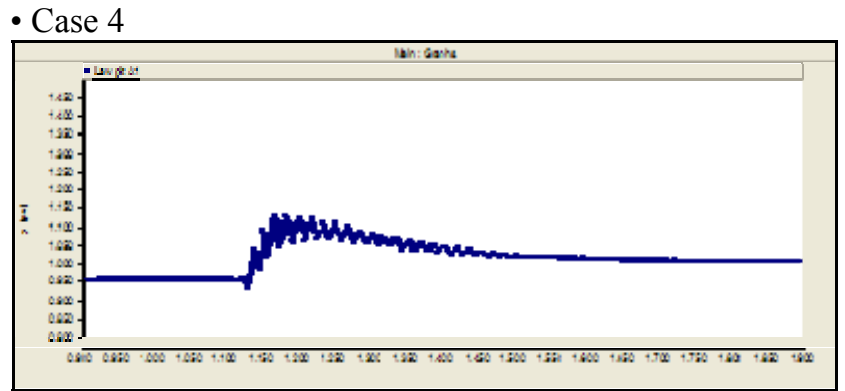

Fig. 12. $132 \mathrm{kV}$ Three phase RMS voltage at Lawpita H/P.

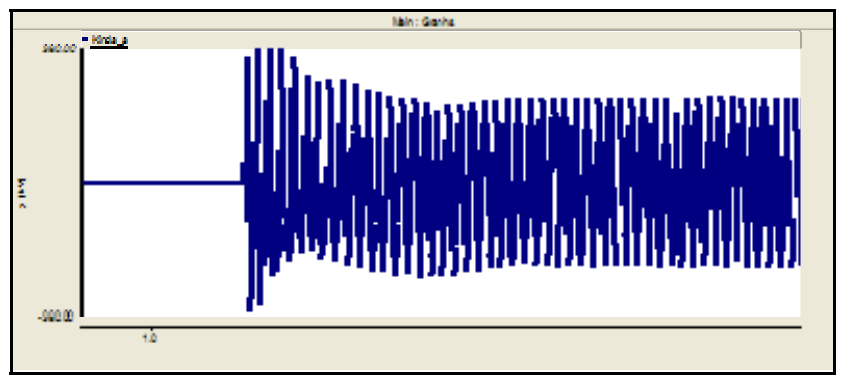

Fig. 13. 132kV Single phase voltage at Kinda H/P.

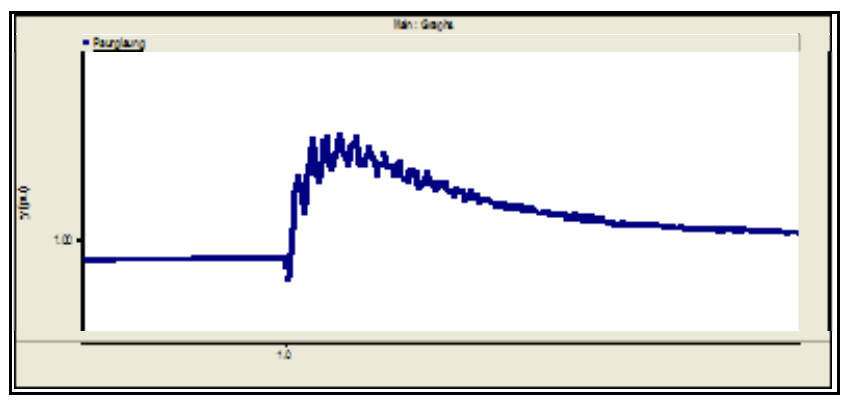

Fig. 14. 230kV Three phase RMS voltage at Paunglaung H/P.

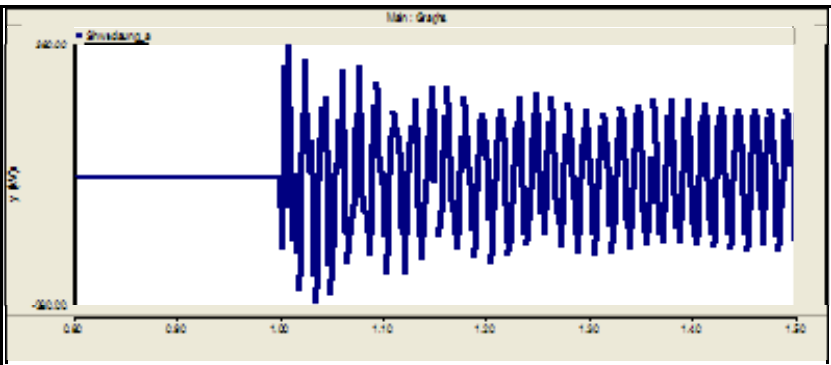

Fig. 15. 230kV Single phase voltage at Shwedaung G/P.

The results of the dynamic simulation confirmed that Cases 1, 3, 4 and 5 have no big transient problems, such as ferro-resonance and self-excitation to charge the primary restorative transmission lines except switching transient phenomena by circuit breaker operation. Switching transient voltages are converged on a normal state. Transient maximum voltages for charging the primary restorative transmission lines are listed in Table. 4. Considering the insulation level of power equipment, transient voltages in Table 4 are reasonable.

Case 2 causes a black-start line charging failure. The system could not tolerate continuous voltage rising any longer, which occurred as a result of the charging capacity of the long distance transmission lines and the transformer changing from $132 \mathrm{kV}$ to $230 \mathrm{kV}$. Therefore, load supply at Thazi $\mathrm{S} / \mathrm{S}$ is required to compensate the charging capacity of the primary restoration lines. Figs. 8 and 9 show that this case is stable because the $45 \mathrm{MW}$ load supply at Thazi S/S balanced the charging capacity of the transmission lines.

Table 4. Transient maximum voltages for initial charging of the lines

\begin{tabular}{c|c|c|c|c|c|c}
\hline & $\begin{array}{c}\text { Terminal } \\
\text { voltage } \\
{[\mathrm{pu}]}\end{array}$ & $\begin{array}{c}\text { Lawpita } \\
230 \mathrm{kV} \\
\text { BUS }\end{array}$ & $\begin{array}{c}\text { Paunglaung } \\
230 \mathrm{kV} \\
\text { BUS }\end{array}$ & $\begin{array}{c}\text { Hlawga } \\
230 \mathrm{kV} \\
\text { BUS }\end{array}$ & $\begin{array}{c}\text { Shwedaung } \\
230 \mathrm{kV} \\
\text { BUS }\end{array}$ & $\begin{array}{c}\text { Kinda } \\
132 \mathrm{kV} \\
\text { BUS }\end{array}$ \\
\hline Case 1 & 0.95 & 1.00335 & 1.17615 & & & \\
\hline Case 2-1 & 0.95 & & 1.08998 & & & \\
\hline Case 3 & 0.95 & 0.982147 & & 1.14572 & & \\
\hline Case 4 & 0.95 & & & & & 1.6112 \\
\hline Case 5 & 0.95 & & 1.02604 & & 1.15619 & \\
\hline
\end{tabular}

\section{Conclusion}

This paper investigated six cases of primary restorative transmission lines by static and dynamic simulation. PSSolution and EMTDC are used for static and dynamic simulation, respectively.

As the results of the simulations, cases 1, 3 and 4 are satisfied with both the reactive power limit of the black-start generators and the overvoltage condition of the receiving end bus. Cases 2 and 6 must be charged after supplying some loads at Thazi $\mathrm{S} / \mathrm{S} 132 \mathrm{kV}$ bus and Taungoo S/S $230 \mathrm{kV}$ bus, respectively, to satisfy the conditions. Case 5 must be charged after switching on the 20MVAr reactive power at Shwedaung S/S. 
Therefore, it is possible for the six cases to be used as primary restorative transmission lines after supplying some loads and reactive power by reactor. However, Paunglaung $\mathrm{H} / \mathrm{P}$ has not been used for black-start generation due to the difficulty in system voltage control during $230 \mathrm{kV}$ system interconnection and the mechanical characteristic. Actually, there was a trial to initially charge Case 5, but this failed. The capacity of gas generators is not enough to act as priority participation generators to cooperate reactive power and the generation of gas turbine power stations is limited day-by-day according to gas supply.

The capacity of Kindda H/P's generators is enough as the priority participation generator to cooperate reactive power. The generators of Lawpita $\mathrm{H} / \mathrm{P}$ which can generate electricity at all times cause a plentiful supply of water even in dry season, and are appropriate for use as black-start generators. And, the generators of Paunglaung H/P, whose capacity is bigger than the others, are appropriate for a priority participation generator to cooperate reactive power when initially charging the long distance transmission lines.

Therefore, Case 1 , the $230 \mathrm{kV}$ transmission lines from Lawpita $\mathrm{H} / \mathrm{P}$ to Paunglaung $\mathrm{H} / \mathrm{P}$, is selected as the main primary restorative transmission lines. And Case 2, which is the $132 \mathrm{kV}$ transmission lines from Lawpita $\mathrm{H} / \mathrm{P}$ to Thazi $\mathrm{S} / \mathrm{S}$, and the $230 \mathrm{kV}$ transmission lines from Thazi $\mathrm{S} / \mathrm{S}$ to Paunglaung $\mathrm{H} / \mathrm{P}$, is selected as the reserve primary restorative transmission lines. Because there were frequent massive or complete blackouts due to faults with Lawpita $\mathrm{H} / \mathrm{P}$, and the Taungoo $\mathrm{S} / \mathrm{S}$ transmission line, it is necessary to prepare a system restoration scenario through the reserve primary restorative transmission lines against permanent faults of the Lawpita $\mathrm{H} / \mathrm{P}$, Taungoo $\mathrm{S} / \mathrm{S}$ transmission line.

\section{References}

[1] E. Mariani, F. Mastroianni and V. Romano, "Field Experiences In Reenergization Of Electrical Networks From Thermal And Hydro Unit," IEEE Trans. on PAS, Vol. 103, No.7, pp. 1707-1713, July 1984.

[2] M. Adibi, P. Clelland, L. Fink, H. Happ, R. Kafka, J. Raine, D. Scheurer and F. Trefny, "Power System Restoration - A Task Force Report," IEEE Trans. on PWRS, Vol. 2, No. 2, pp. 271-277, May 1987.

[3] M. M. Adibi et al., "Power System Restoration Issues," IEEE Computer Applications in Power, Vol. 4, No. 2, pp. 19-24, April 1991.

[4] M. M. Adibi and R. W. Alexander, "Overvoltage Control During Restoration (Power System Restoration Working Group Report)," IEEE Trans. on PWRS, Vol. 7, No. 4, pp. 1464-1470, November 1992.

[5] M. M. Adibi et al., "Special Consideration in Power System Restoration The Second Working Group Report," IEEE Trans. On PWRS, Vol. 9, No. 1, pp. 15-21, February 1994.

[6] M. M. Adibi et al., "Reactive Capability Limitation of Synchronous Machines," IEEE Trans. on PWRS, Vol. 9, No. 1, pp. 29-40, February 1994.
[7] H. J Lee et al., "Analysis of The Primary Restorative Transmission System," IFAC Symposium 2003.

[8] I. J. Song and N. H. Lee., "Development of the Primary Restorative Transmission System Analyzer to Restore Massive Blackout," International Conference on Electrical Engineering 2004/ Sapporo, Japan, July 4-8, 2004.

[9] H. J Lee et al., "Analysis of the Harmonic Resonance during Energizing the Primary Restorative Transmission Systems," 2005 IEEE St.Petersburg Power Tech, May 25-30, 2005.

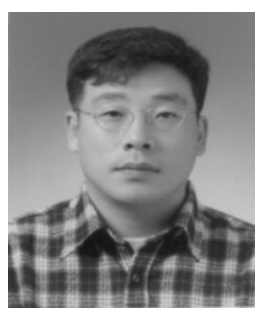

Yong-Hak Kim received his B.S., M.S. and $\mathrm{Ph} . \mathrm{D}$. degrees in electrical engineering from Chonnam National University, Korea, in 1994, 1996 and 2005, respectively. He is a senior member of Technical Staff in T\&D Lab. of Korea Electric Power Research Institute (KEPRI), a research center of Korea Electric Power Corporation (KEPCO). His interests include power system stability, modeling and substation automation systems.

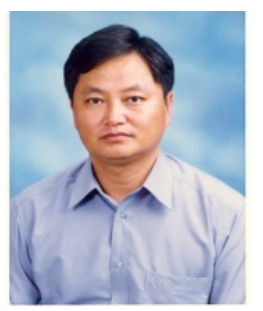

In-Jun Song received his B.S., M.S. and $\mathrm{Ph} . \mathrm{D}$. degrees in electrical engineering from Chonbuk National University, Korea, in 2000. He is a senior member of Technical Staff in Transmission and Distribution Lab. of Korea Electric Power Research Institute (KEPRI), a research center of Korea Electric Power Corporation (KEPCO). His interests include auto restoration systems and substation automation systems.

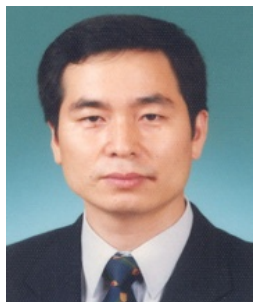

Byung-Tae Jang received his B.S. degrees in electrical engineering from Busan National University, Korea, in 1990, and his M. S. degrees in electrical engineering from Chungnam National University, Korea, in 1999. He is currently a senior member of the Korea Electric Power Research Institute and a P.E. of Electrical Engineering. His research interests include power system protection and control, and substation automation system.

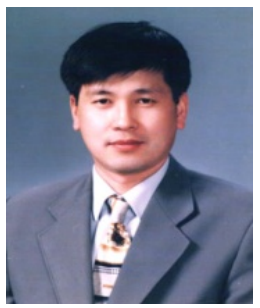

Yong-Ho An received his B.S. and M.S. degrees in electrical engineering from Chonbuk National University, Korea, in 2000 . He is a principal member of Technical Staff in Transmission and Distribution Lab. of Korea Electric Power Research Institute (KEPRI), a research center of Korea Electric Power Corporation (KEPCO). His interests include substation automation systems and power system protection. 